\title{
Validation of serum gamma-glutamyl transferase activity and body weight information for identifying dairy calves that are too young to be transported to auction markets in Canada
}

\author{
S. Buczinski, ${ }^{1 *}$ ๑ J. Dubuc, ${ }^{1}$ ๑ V. Bourgeois, ${ }^{1} \odot$ P. Baillargeon, ${ }^{2}$ N. Côté, ${ }^{2}$ and G. Fecteau ${ }^{1}$ \\ ${ }^{1}$ Département des sciences cliniques, Faculté de médecine vétérinaire, Université de Montréal, Saint-Hyacinthe J2S 2M2, Québec, Canada \\ ${ }^{2}$ Producteurs bovins du Québec, Longueuil, J4H 4G2, Québec, Canada
}

\begin{abstract}
Dairy calves are at risk of being stressed when transported during the first week of life. A new Canadian federal rule will forbid transportation of calves younger than $9 \mathrm{~d}$ old to auction market. However, in the absence of reliable information to determine birth date, other indirect methods would be of interest. This study aimed to determine the prediction accuracy of body weight, Brix refractometry, and serum gammaglutamyl transferase (GGT) activity for determining if a calf was not fit to be transported (i.e., $<9 \mathrm{~d}$ old). For this purpose, we used 284 calves with a known birth date from a cross-sectional and a prospective cohort study. A logistic regression model was built based on multivariable analysis as well as a misclassification cost term analysis. Because of the collinearity between GGT activity and Brix value and lower discrimination of Brix value, the GGT activity was retained for the main model. The final logistic regression model contained body weight and log-transformed GGT activity value. The misclassifications of the logistic model was minimized using a model probability threshold $\geq 0.55$ with a sensitivity of $70.4 \%$ and a specificity of $77.3 \%$. This probability threshold was relatively robust for various prevalence and false negative to false positive cost ratios. The prediction accuracy of this model was moderate at the individual level, but is helpful in calves with a reasonable suspicion of being less than $9 \mathrm{~d}$ old. Key words: well-being, young calf
\end{abstract}

\section{INTRODUCTION}

Calves are born agammaglobulemic because of the epitheliochorial placentation in ruminants (Weaver et

Received September 17, 2019.

Accepted October 31, 2019.

*Corresponding author: s.buczinski@umontreal.ca al., 2000). They depend on timely absorption of colostrum, in particular IgG, to protect them from infectious challenges in early extra-uterine life (Godden, 2008). The concentration of serum $\operatorname{IgG}$ is used to measure the transfer of passive immunity (TPI) in calves from 1 to $8 \mathrm{~d}$ of age (Wilm et al., 2018). The serum IgG concentration can be quantified directly or indirectly using refractometry (Weaver et al., 2000). Different thresholds have been recommended to characterize inadequate TPI using a refractometer in grams per deciliter or \% Brix scale. The benchmark concentration of serum IgG $\geq 10 \mathrm{~g} / \mathrm{L}$ has been traditionally used to define successful TPI (Buczinski et al., 2018). When colostrum is fed to young calves, other metabolites or cells can be absorbed and found in the calf blood. Serum gammaglutamyl transferase (GGT) activity is one of these colostrum components (Braun et al., 1982). Serum GGT activity is therefore extremely elevated in young calves (>500 to $1,000 \mathrm{IU} / \mathrm{L})$ and then decreases slowly over time (Parish et al., 1997; Ježek et al., 2006). Calves 3 to $4 \mathrm{wk}$ old have GGT concentrations comparable to adult serum GGT activity, which is generally less than 50 IU/L (Ježek et al., 2006; Găvan et al., 2010).

In Canada, most male calves from the dairy industry are transported to the auction market to be raised in veal calf feeding units (Renaud et al., 2018b). The dilemma for dairy farmers is to determine the optimal moment for the calf to leave the farm of origin. This may be influenced by the cost of feeding male calves for extra days as well as the limited space available for raising male calves. Moreover, the relatively volatile market of dairy calves price often prevents investment in this aspect of the dairy farm. From a regulatory perspective in Canada, the minimal age for transportation was not clearly defined until recently (Canadian Government, 2019). It is difficult to provide an evidence-based guideline for the minimal age requirement to be transported because the effect of transportation on young calf physiology is complex. For example, 3 -dold calves have different behavior (more lying down 
time) and metabolic responses (increased creatine kinase and BHB concentration) during $12 \mathrm{~h}$ of transportation versus 5 - or 10 -d-old calves (Jongman and Butler, 2014). The transportation effect on calf welfare depends on many other factors such as management before transport, loading, transport environment (with other animals grouping and physical characteristics), climatic and driving conditions, as well as total journey time as previously reviewed (Nielsen et al., 2011).

In Canada, the national code of practice for the care and handling of veal calves promotes buying calves that are older than $14 \mathrm{~d}$ (NFACC, 2017). In the European Union where the majority of veal calf production occurs, long transportation is forbidden for calves $<14 \mathrm{~d}$ old (Animal Transport Guides EU, 2019). In New Zealand and Australia where dairy calves are traditionally sold to slaughter during the first weeks of age, calves should be at least 4 full days old to be transported for the purpose of sale or slaughter (New Zealand Legislation, 2018). In February 2020, Canadian federal regulations of transport will forbid transportation of calves $<9 \mathrm{~d}$ to auction markets (Canadian Government, 2019).

In Québec, Canada, it is mandatory to physically identify calves at birth with an ear tag and relay this information into the provincial database Agri-Tracabilité Québec (https://www.atq.qc.ca/en/). However, it is not possible to access the age information during the transportation of calves to the auction market and subsequently from the auction market to the veal farms. The inscription to this registry may also be inaccurate for some calves. Body weight upon arrival in a veal farm, which is an indirect marker of age, has been negatively associated with increased risk of mortality (Winder et al., 2016) and positively associated with ADG (Renaud et al., 2018b) in Ontario milk-fed veal calves. Using BW estimation and blood markers that can be affected by calves' age could therefore potentially be a helpful way to determine if calves are old enough to be transported based on federal regulation. This information would be helpful to discourage transportation of calves $<9 \mathrm{~d}$ old, thus improving calves' welfare and health during their journey and their feeding period in veal farms.

The objective of the study was therefore to quantify the association between the age of calves and various predictors such as serum GGT activity, serum Brix refractometry, and calves' BW. Our hypothesis was that GGT and potentially other predictors could be used for accurately identifying $<9$-d-old calves. As a secondary objective, we were interested in determining the accuracy of our prediction model in various clinical contexts to try to minimize misclassification costs due to application of the model.

\section{MATERIALS AND METHODS}

The current study used data from 2 different studies conducted on dairy calves from multiple clients of the bovine ambulatory clinic of the Faculté de médecine vétérinaire of the Université de Montréal (St-Hyacinthe, QC, Canada) during the summer and fall of 2018. The main study characteristics are summarized in Figure 1. The calves included this study came from 2 different research projects settings on young calves' health with one prospective cohort study (with weekly visits on the same dairy farms and sampling calves in their first month of life) and one cross-sectional study. The research protocol was accepted by the animal care committee of the Université de Montréal (18-Rech-1966). Calves were not sampled if apparently sick (as determined by clinical observation specifically looking for signs of depression, abnormal respiratory pattern, and umbilical assessment) or dehydrated (which was assessed observing eye position in the orbit). This examination strategy was performed by a veterinarian or a research technician both having relevant experience in health assessment of calves. This examination strategy was judged compatible with what could be further used by the industry to focus on apparently healthy calves.

\section{Prospective Cohort Study}

The first data set used originated from an ongoing trial conducted in 9 dairy farms that were visited weekly to evaluate TPI during the first week of life. All calves at least $24 \mathrm{~h}$ old were sampled at each visit during their first $4 \mathrm{wk}$ of life. Calves were sampled if they were physically present at the farm. One to 4 samples were therefore collected from each calf. A random selection from the cohort study was performed. The data set was developed based on an expected median age of $8 \mathrm{~d}$ with only 1 datum per calf (to avoid repeated measures at different moments for a specific calf). This cut-off was chosen because it was relevant to split the data set with the same number of calves $<9$ d old versus $\geq 9$ d old, therefore ensuring a minimal prevalence of the event to predict to improve model identifiability.

\section{Cross-Sectional Study}

A convenient sample of 7 herds was selected within the bovine ambulatory clinic client list. Herds were recruited if they were milking more than 80 cows, interested in participating in the study, and kept their male calves for at least the first 5 to $7 \mathrm{~d}$ of life on the farm. Herds were visited between 1 and 3 times 21 to $28 \mathrm{~d}$ 
apart. All calves (male and female) older than $24 \mathrm{~h}$ of age and less than $28 \mathrm{~d}$ of age were sampled. Each calf was sampled only once for this part of the study.

In both studies, data collected at the calf level were sex, birth date using validated herd registry, and heart girth (HG; cm). A jugular venous blood sample was also taken with a $20-\mathrm{G}$ needle, stored in a dry tube, and allowed to clot before being centrifuged at 1,750 $\times$ $g$ for $10 \mathrm{~min}$ at $20^{\circ} \mathrm{C}$. A fraction of the serum sample was then used for determination of refractance using a validated digital Brix refractometer (Misco, Palm Abbe, Solon, $\mathrm{OH}$ ). The serum samples were stored at $-20^{\circ} \mathrm{C}$ until GGT analysis was performed. The samples were then analyzed in the same batch using a Beckman Coulter analyzer using Synchron system in a veterinary diagnostic laboratory (Biovet, St-Hyacinthe, QC, Canada).

Data were compiled in an Excel spreadsheet (Microsoft Corp., Redmond, WA). The HG was used to estimate calves' BW based on previously published research (Heinrichs et al., 1992) using the following equation:

$$
\mathrm{BW}=100.49-2.83 \mathrm{HG}+0.02636 \mathrm{HG}^{2} .
$$

Body weight was also considered as a useful measure correlated with the age of the calf and negatively associated with mortality risk in veal farms (Winder et al., 2016) as well as a potential factor interacting with transport condition as a stressor in calves (Masmeijer et al., 2019).

\section{Sample-Size Justification}

The accuracy of a new diagnostic test or predictive model can be based on different measures including sensitivity, specificity, and its discrimination capacity. The area under the receiving operating characteristics curve (AUC) determines the discrimination of the test among patients with and without the event of interest (i.e., calf less than $9 \mathrm{~d}$ old). The AUC varies from 0 to 1 , with AUC $>0.5$ indicating a test better than chance alone. Diagnostic tests of clinical interest have traditionally been defined as tests with $\mathrm{AUC} \geq 0.8$ (Mandrekar, 2010). We based our sample size justification on the required number of calves to detect an AUC of 0.8 or greater with a 0.1 margin (Hajian-Tilaki, 2014). A minimum of 100 calves per group ( $\leq$ vs. $>$ age threshold) was therefore estimated to be necessary.

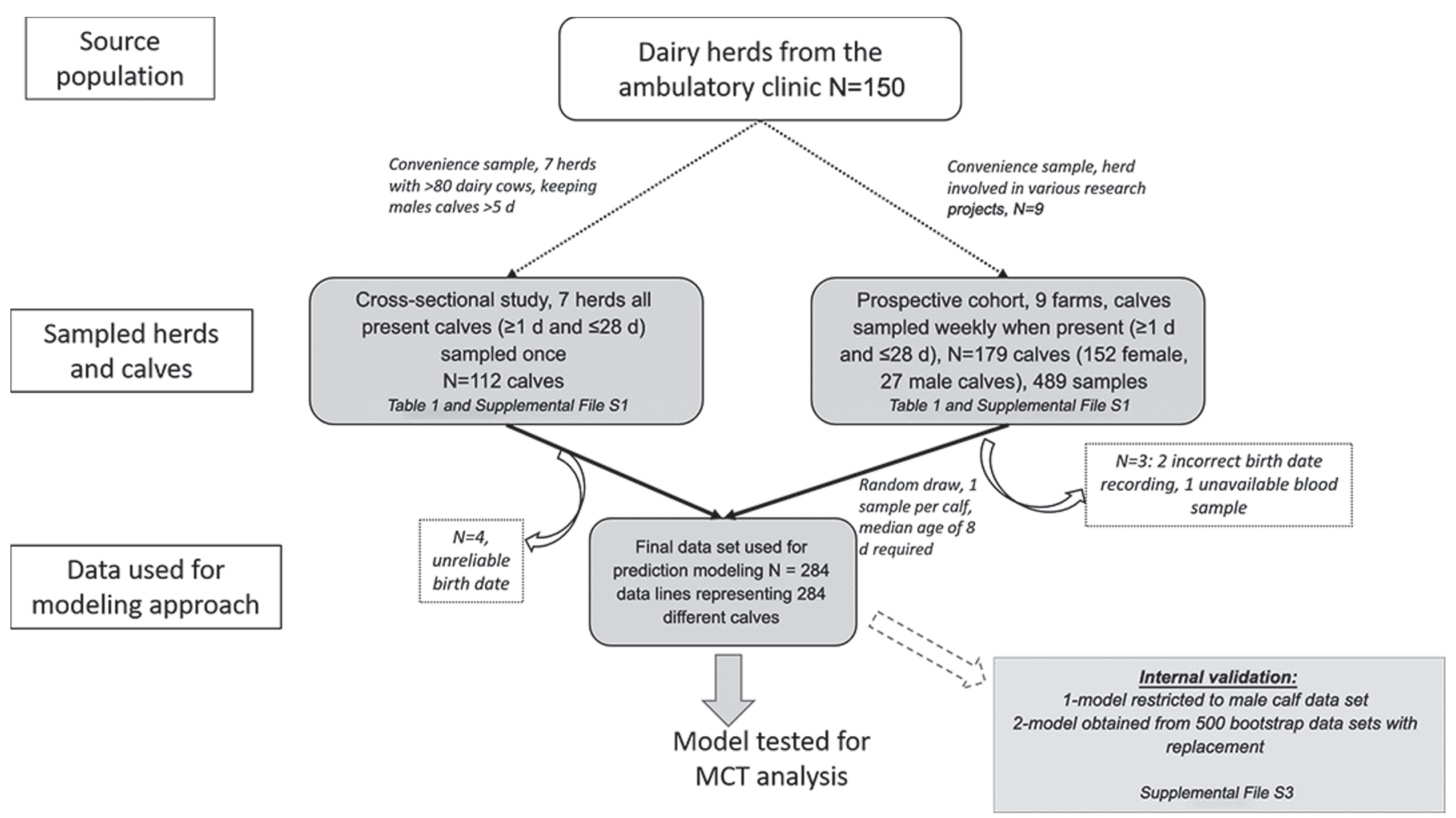

Figure 1. Flow diagram of the modeling approach used. The data set used for multivariable analysis comes from one cross-sectional study with calves sampled during their first months of life. The second part of the data is a random draw from a prospective cohort where calves were sampled weekly during their first month of life. The final data set is from 284 samples from 284 different calves between $24 \mathrm{~h}$ and $28 \mathrm{~d}$ of life. Supplemental files are available at https://doi.org/10.3168/jds.2019-17601. MCT = misclassification cost term. 


\section{Statistical Analyses}

Descriptive statistics in longitudinal and cross-sectional study were performed using commercial software (SAS v9.4, SAS Institute Inc., Cary, NC). For normally distributed data (using Shapiro-Wilk test), the means (SD) were reported, whereas median (reference range) were reported for non-normally distributed data. The proportion of calves having a successful TPI as determined using $\geq 8.4 \%$ Brix cut-off (Deelen et al., 2014) was compared between male and female calves using a chi-squared test in every study. A random selection from the longitudinal study data set (containing only one data per calf with a median age of the sampled population fixed at $8 \mathrm{~d}$ old) was obtained and merged with the cross-sectional study. This final data set contained only one data line per calf and was further used for modeling. In all analyses, the age of the calf was the dependent variable.

Because the objective was to predict calves that were transported too young (i.e., unfit for transportation), the age was dichotomized based on the thresholds $<9$ versus $\geq 9 \mathrm{~d}$ (which is the legal required age for transportation in the auction market in Canada). The optimal GGT threshold for this database was defined based on the Youden index, which maximizes the sum of sensitivity (proportion of calves $<9$ d old correctly predicted) and specificity (proportion of calves $\geq 9 \mathrm{~d}$ old correctly predicted). Logistic regression models were then used to account for other covariates. Correlogram between covariates of possible models (weight, GGT activity, and Brix refractance) was assessed using a Spearman rank correlation with collinearity defined as rho $>0.6$ (CORR procedure in SAS). Logistic regression models were built for predicting calves that were unfit to be transported based on their minimal age (calves $<9 \mathrm{~d}$ old). In this model, log-transformed serum GGT activity was used as a continuous variable to avoid pitfalls of categorization (Collins et al., 2016). The fit of the model was assessed using Hosmer and Lemeshow test (Hosmer et al., 1997). The prediction of the main model (lnGGT and weight) was assessed using discrimination and calibration indices (Fenlon et al., 2018). The discrimination of the model was assessed using calculation of the AUC. A calibration plot using the deciles of predicted probability versus observed probability of anomalies was also constructed as a visual way to determine the correlation between predicted and observed probabilities (Fenlon et al., 2018).

Finally, optimization of prediction was obtained based on the sensitivity and specificity of the main model using different thresholds of predicted probabilities to define a calf $<9$ d old. In classical logistic regression model, the sensitivity and specificity of the model is based on using the predicted probability higher versus lower than 0.5 . A calf with a predicted probability $<0.5$ would be predicted as a calf without the event to predict (i.e., $9 \mathrm{~d}$ old or more) and a predicted probability $\geq 0.5$ would be define a calf too young to be transported (i.e., $<9$ d old). The model sensitivity and specificity are then derived by the cross-classification results of predicted versus observed age. Optimization of the prediction model is based on looking for the effect of changing the prediction probability threshold to see its effect on sensitivity and specificity. For achieving that particular goal, the prediction of the main model was either a calf with an adequate age (if predicted probability using logistic regression $<$ threshold probability) or younger (if predicted probability $\geq$ threshold probability) and the sensitivity/specificity of the model at a specific threshold was then obtained. This process was repeated for different thresholds of predicted probability by the model (from 0.05 to 0.95 with 0.05 steps). The probability cut-off with the maximal sum of sensitivity + specificity was defined as the optimal threshold of prediction for the model.

The optimal cut-off was further refined accounting for the difference costs of a false negative versus false positive calf. A false positive case was $\geq 9$-d-old calf inadequately classified as unfit to be transported with potential penalties for the producer. By contrast, a false negative calf would be a young calf that should not be allowed to be transported $(<9 \mathrm{~d}$ old $)$ that is not detected by the model. In this case, this calf should not have been allowed to be transported. Because it is difficult to determine the exact cost of these 2 types of misclassifications, we performed misclassification cost term (MCT) analysis using the following equation:

$$
\mathrm{MCT}=(1-\mathrm{p}) \times(1-\mathrm{Sp})+\mathrm{r} \times \mathrm{p} \times(1-\mathrm{Se}),[2]
$$

where $\mathrm{p}$ is the prevalence of calves less than $9 \mathrm{~d}$ of age, $\mathrm{r}$ is the relative cost between false negative and false positive cases, Sp is the specificity, and Se is the sensitivity. In the absence of specific data concerning this ratio, we used plausible ranges of $5: 1,3: 1,1: 1,1: 3$, and 1:5, which accounted for various production contexts (contexts where the costs of penalizing a producer are high vs. contexts where welfare concerns are higher than penalizing a false positive case). These variable scenarios would be especially useful to determine stability of the model depending on the context where it is intended to be used. Wet umbilical stalks generally dry in 2 to $8 \mathrm{~d}$ in dairy calves (Hides and Hannah, 2005). Because we recently found that up to $12 \%$ of calves 
with neonate characteristics such as wet umbilical stalk are present in Québec auction markets (Marquou et al., 2019), 3 different scenarios of plausible prevalence of calves $<9$ d were used (i.e., 10, 20, and $40 \%$ ) for this approach.

\section{RESULTS}

\section{Descriptive Statistics}

The flow diagram summarizing the initial population and the data set for logistic regression is depicted in Figure 1. A total of 179 calves were enrolled in the prospective cohort study (152 females and 27 male calves). One to 4 samples per calf was available. Three calves were excluded due to unavailable sample (n $=1)$ or incorrect birth date recording $(\mathrm{n}=2)$. The prevalence of inadequate TPI (defined as Brix values $<8.4 \%$ in calves between 1 to $8 \mathrm{~d}$ old) was 34 and $48 \%$ in females and males, respectively $(P=0.17)$. A total of 112 calves were included in the cross-sectional study. Four calves were excluded due to incorrect birth date recording. One hundred eight calves were therefore available in this data set. The prevalence of inadequate TPI in females and males was 50 and $61 \%$, respectively $(P=0.47)$. Descriptive results are presented in Table 1 and Supplemental File S1 (https://doi.org/10.3168/jds .2019-17601) for the 2 different data sets.

\section{Logistic Regression Model}

The final database used for model building included 284 calves (108 calves from the cross-sectional study and 176 calves from the prospective cohort) with 1 unique sample per calf between 1 and $28 \mathrm{~d}$ of age with 65 male calves (23\%). A total of 152 calves (53.5\%) were less than $9 \mathrm{~d}$ old. The distribution of calves according to their sex, weight, serum GGT activity, and age in this final data set is represented in Figure 2. The refractance of the serum and GGT concentration were highly correlated (Spearman rho $=0.61$ ). The GGT was preferred over Brix in multivariable models due to its wider variation range. The Youden index of GGT for predicting calves $<9$ d old was $59.9 \%$ sensitive and $84.1 \%$ specific using a cut-off $>237 \mathrm{IU} / \mathrm{mL}$. The univariable and multivariable analyses are described in Table 2. The final model included log-transformed GGT and calf weight. The discrimination of the model as determined by the AUC was 0.794 (95\% CI: 0.7410.846), which is compatible with a good discrimination ability (Steyerberg et al., 2010). The calibration plot of the model described the mean observed probability by decile of the data set versus the observed probability (Figure 3). The mean predicted probability or its 95th confidence interval was generally close to the identity line (i.e., truly observed probability).

\section{Optimal Probability Model}

The optimal probability cut-off to define a calf that is unfit for transport ( $<9$ d-old) was for a predicted probability equal or greater than 0.55 . Using this threshold, sensitivity is estimated to $70.4 \%$ and specificity is $77.3 \%$. The risk of misclassified calves is also minimized (Table 3, Figure 4A). The MCT analysis is also presented in the same figure based on various scenario of unfit calves' prevalence and various false negative: false positive cost ratios (Figure 4B, C, and D). The analysis of the different scenarios of prevalence revealed that the optimal probability cut-off (0.55) was relatively robust. Increasing the probability threshold was only beneficial in situations where the cost of false positive cases was high (with false negative: false positive costs ratio of $1: 3$ and 1:5) in the 20 and $40 \%$ prevalence scenarios. However, the MCT decrease was relatively small in these cases.

Table 1. Descriptive statistics of the cross-sectional (A) and longitudinal (B) data $\operatorname{sets}^{1}$

\begin{tabular}{lccccc}
\hline Item & Mean & Median & IQR & Minimum & Maximum \\
\hline Data set A & & & & & \\
Age (d) & 10 & 8 & to 15 & 1 & 28 \\
Brix (\%) & 8.1 & 8.0 & 7.6 to 8.4 & 6.3 & 10.1 \\
GGT (IU/L) & 206 & 80.5 & 54 to 249 & 32 & 2,048 \\
Ln(GGT) & 4.72 & 4.39 & 3.98 to 5.52 & 3.09 & 7.63 \\
Weight (kg) & 45.2 & 43.9 & 41.2 to 48.5 & 34.2 & 60.9 \\
Data set B & & & 5 to 12 & 1 & 28 \\
Age (d) & 7.5 & 8 & 7.8 to 8.9 & 6.3 & 12.4 \\
Brix (\%) & 8.4 & 8.3 & 77 to 357 & 10 & 2.30 \\
GGT (IU/L) & 171 & 164 & 4.71 to 6.03 & 7.66 \\
Ln(GGT) & 5.40 & 5.43 & 42.6 to 50.1 & 29.9 & 75.8 \\
Weight (kg) & 45.6 & 45.4 & &
\end{tabular}

${ }^{1} \mathrm{IQR}=$ interquartile range; GGT = gamma-glutamyl transferase. 


\section{DISCUSSION}

According to the results of this study, GGT and BW determined by HG measurements could be used to detect calves too young to be transported based on Canadian federal transport regulation (i.e., $<9 \mathrm{~d}$ old). However, the accuracy of this approach appears limited at the individual level because the estimated sensitivity and specificity were, respectively, 70.4 and $77.3 \%$ when using the optimized cut-off. The optimal selection of probability threshold ultimately depended on the context of intended use for the model as demonstrated by the MCT analysis. The initial intended use of the model was to detect unfitted individual animals. However, the estimated accuracy of the model does not justify this use. Using Bayes theorem, which can be used for linking pre-test probability to post-test probabilities based on likelihood ratio of a specific test results, it is relatively easy to illustrate test accuracy in various clinical contexts (Timsit et al., 2018). The post-test odds of disease probability obtained by the product of pre-test odds and likelihood ratio of test result. Using the model for a calf with no specific information on age and assuming a 50/50 probability of being unfit for transport (i.e., nonspecific pre-test information), the post-test probability of the calf to be $<9 \mathrm{~d}$ old using the 0.55 probability cut-off (from model regression) returned a post-test probability of $75.6 \%$ if the test is positive and $27.7 \%$ if the test is negative (Timsit et al., 2018). However, using the model in case of high suspicion of an unfitted calf (e.g., umbilical cord not completely dried) would return a post-test probability of $92.5 \%$ assuming that the pre-test probability is $80 \%$ or higher (vs. post-test probability of $60.5 \%$ if the test

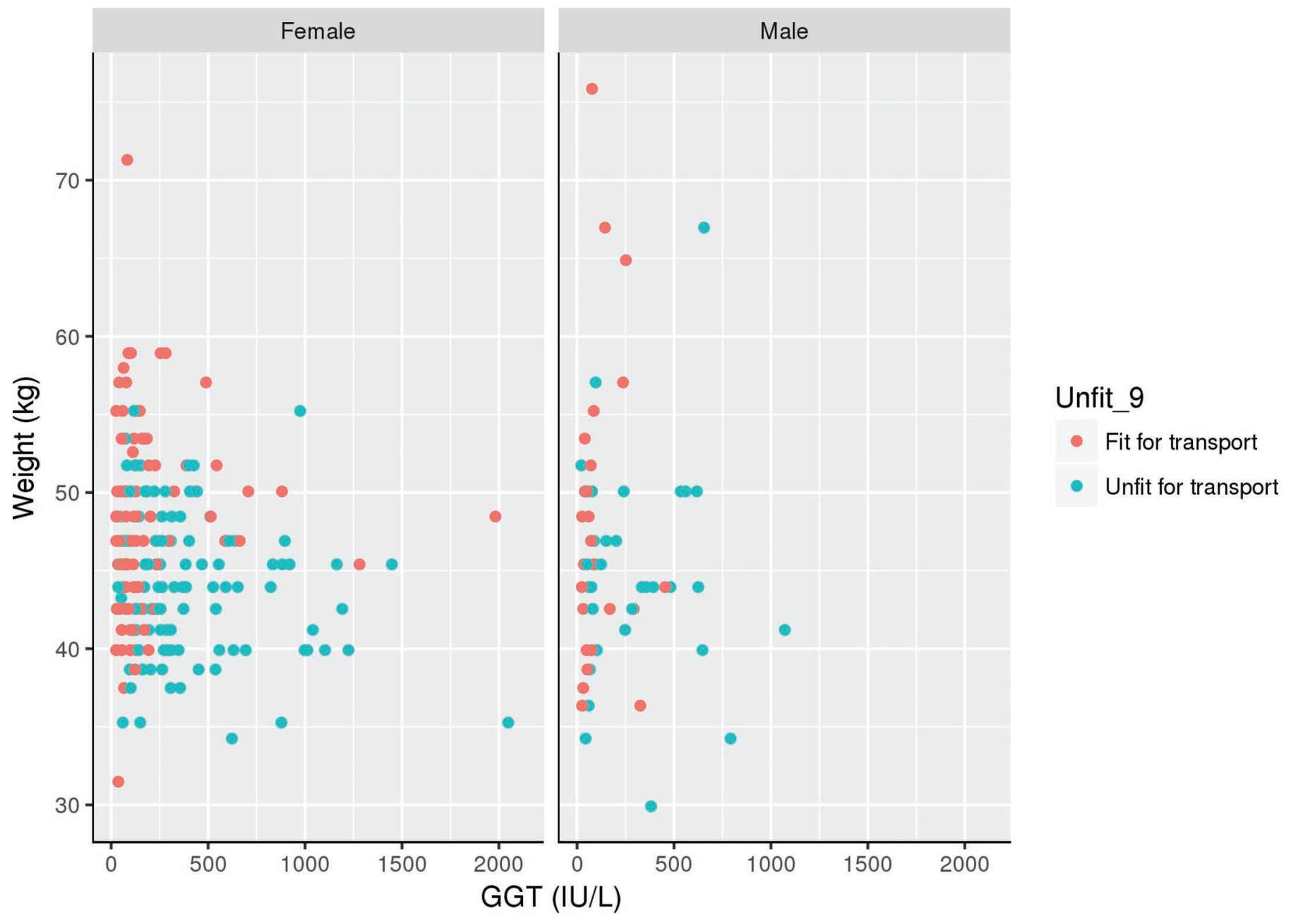

Figure 2. Description of the calves' population characteristics used in the final logistic regression modeling. This 2-panel figure represents the distribution of male and female calves used for prediction modeling according to their serum gamma-glutamyl transferase (GGT) activity. The calves are further identified as $<9 \mathrm{~d}$ old (green dots, unfit for transport) versus $\geq 9 \mathrm{~d}$ old (orange dots, fit for transport). 
Table 2. Univariable and multivariable analyses of the merged databases with 284 calves for predicting calves less than $9 \mathrm{~d}$ old (i.e., calves unfit to be transported to auction markets in Canada) ${ }^{1}$

\begin{tabular}{|c|c|c|c|c|c|}
\hline Model & Estimate & $\mathrm{SE}$ & OR & $95 \% \mathrm{CI}$ & $P$-value \\
\hline \multicolumn{6}{|c|}{ Univariable analysis } \\
\hline \multicolumn{6}{|c|}{ Data set } \\
\hline Intercept & 0.12 & 0.12 & - & - & 0.32 \\
\hline Cross-sectional & Referent & - & - & - & - \\
\hline Longitudinal & -0.08 & 0.12 & 0.845 & $0.523-1.366$ & 0.49 \\
\hline \multicolumn{6}{|l|}{ Sex } \\
\hline Intercept & 0.21 & 0.14 & - & - & 0.14 \\
\hline Male & Referent & - & - & - & - \\
\hline Female & -0.13 & 0.14 & 0.771 & $0.441-1.351$ & 0.36 \\
\hline \multicolumn{6}{|l|}{$\ln (\mathrm{GGT})$} \\
\hline Intercept & -5 & 0.77 & - & - & $<0.0001$ \\
\hline 1-unit increase & 1.01 & 0.15 & 2.743 & $2.045-3.680$ & $<0.0001$ \\
\hline \multicolumn{6}{|l|}{ Weight $(\mathrm{kg})$} \\
\hline Intercept & 5.075 & 1.11 & - & - & $<0.0001$ \\
\hline $1-\mathrm{kg}$ increase & -0.11 & 0.02 & 0.897 & $0.856-0.941$ & $<0.0001$ \\
\hline \multicolumn{6}{|l|}{$\operatorname{Brix}(\%)$} \\
\hline Intercept & -5.84 & 1.41 & - & - & $<0.0001$ \\
\hline $1 \%$ increase & 0.71 & 0.17 & 2.032 & $1.462-2.825$ & $<0.0001$ \\
\hline \multicolumn{6}{|c|}{ Multivariable (main) model } \\
\hline Intercept & -0.12 & 1.36 & - & - & 0.93 \\
\hline \multicolumn{6}{|l|}{$\ln (\mathrm{GGT})$} \\
\hline 1-unit increase & 1.06 & 0.16 & 2.877 & $2.092-3.959$ & $<0.0001$ \\
\hline \multicolumn{6}{|l|}{ Weight (kg) } \\
\hline 1-kg increase & -0.11 & 0.03 & 0.894 & 0.849-0.941 & $<0.0001$ \\
\hline
\end{tabular}

is negative). This has some interesting features because it would transform a relatively subjective suspicion (visual observations of the umbilicus) into a true objective measurement (probability of being $<9$ d old; Timsit et al., 2018). This could help a regulatory agency to document illegal situations. One of the potential uses of the presented model in practice would therefore be as a monitoring tool at the population level to estimate the true prevalence of unfitted calves based on apparent prevalence and test accuracy rather than at the individual calf level. For example, monitoring the prevalence of calves that are declared too young to be transported by the model could be back-transformed in the true prevalence of calves $<9 \mathrm{~d}$ old using model sensitivity and specificity (Dohoo et al., 2009). Interestingly, the GGT and multivariable models were also useful in our sample population for detecting calves $<4 \mathrm{~d}$ old (New Zealand requirement) and $<14 \mathrm{~d}$ old (European Union age limitation for long transportation). The optimal GGT threshold was $>345 \mathrm{IU} / \mathrm{L}$ for detecting calves $<4 \mathrm{~d}$ old with $77 \%$ sensitivity and $86 \%$ specificity. The optimal GGT threshold was $>116 \mathrm{IU} / \mathrm{L}$ for detecting calves $<14 \mathrm{~d}$ old with $71 \%$ sensitivity and $80 \%$ specificity. Multivariable models are presented in Supplemental File S2 (https://doi.org/10.3168/jds .2019-17601).

In the absence of specific data that could be directly collected at the auction market (especially for age determination), we used data obtained from dairy farms where birth registry was reliable. This may introduce a bias because a relatively higher percentage of female calves was represented. The model is also limited to calf populations where the prevalence of inadequate transfer is higher than the dairy industry benchmark. In our study, between 30 to $50 \%$ of calves suffered from inadequate TPI. Various ranges of inadequate TPI have been described in veal calves. Previous studies from Belgium and Portugal found 41.3\% (Pardon et al., 2015 ) and $38 \%$ of calves (Stilwell and Carvalho, 2011) with inadequate TPI, respectively. A lower prevalence of inadequate TPI has also been reported [21\% of calves upon arrival at an Ontario veal farm using an ELISA snaptest (Renaud et al., 2018a) and $20 \%$ of calves with total protein concentration $<6.0 \mathrm{~g} / \mathrm{dL}$ in an Ohio veal facility (Pempek et al., 2017)]. In Québec, limited information is available. However, we recently found that more than $50 \%$ of calves had serum TS $<5.2 \mathrm{~g} / \mathrm{dL}$ in a previous trial (Berman et al., 2017).

Dosage of GGT is not as practically feasible as Brix refractance assessment. However, the models that included Brix concentration had lower discrimination capacity $(\mathrm{AUC}=0.737$; i.e., out of the $95 \%$ CI from the main model AUC, data not shown) and lower accuracy than the model including GGT (Supplemental File S3; https://doi.org/10.3168/jds.2019-17601). This may be due to relatively low Brix concentration variability relative to the measurement tool available. Moreover, the variability of serum refractance with time may be 
complex due to calf own protein synthesis, which can therefore interfere with serum refractance (Villarroel et al., 2013; Wilm et al., 2018). Hydration status of the calves could also have a significant effect on serum component concentration (Fecteau et al., 2013). All the calves in the present study had normal hydration status and were apparently healthy. The current study finding should therefore not be extrapolated to dehydrated or sick calves.

The main interest for completing the present study was to find a way to distinguish calves fit or unfit for transportation in the absence of a specific birth registry. The federal transportation law effective in early
2020 will need some tools to help monitor the status of sold calves. An easier way to determine calf age would be to have a fast and reliable access of birth registry before the calf is transported or when assessing the calf directly at the auction market. However, this is not possible now in Canada. Our method would be an efficient solution that should be directly applied before the calves would be transported to the auction market, avoiding unnecessary unfitted stress and eventual penalties for the farmer. In Québec, the identification of the calf with a unique official ear tag should be applied within $7 \mathrm{~d}$ after birth or before the calf leaves the farm. Then the ear tag should be officially activated within 7

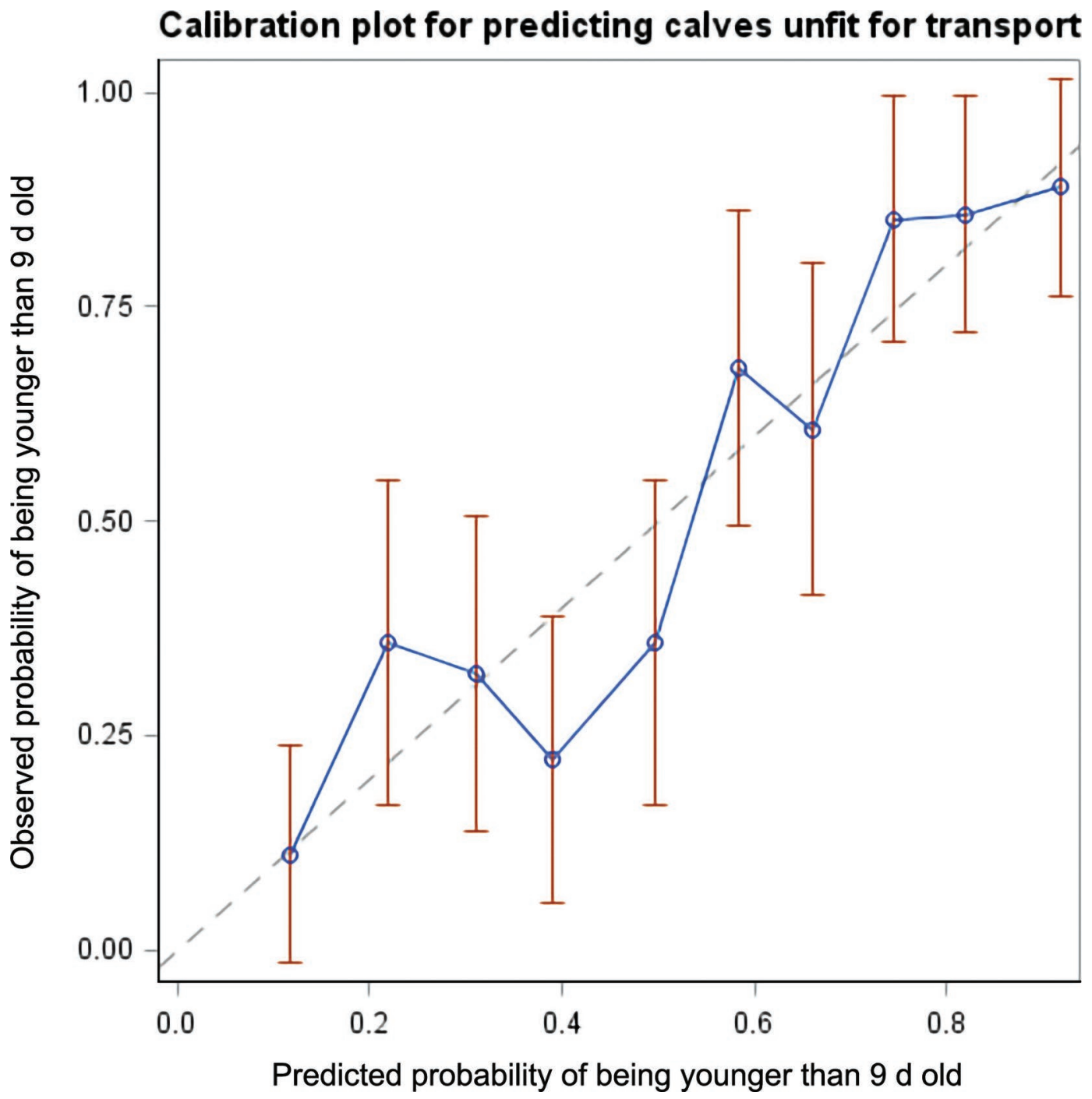

Figure 3. Calibration plots using the predicted versus observed probability of the calves being unfit for transport based on federal Canadian transport regulations (i.e., $<9 \mathrm{~d}$ old). This plot was obtained by dividing the predicted probabilities obtained from the logistic regression model into 10 deciles. The mean observed probability of the corresponding calves is then compared with the mean predicted probability for that specific decile. The CI are indicated by the red whiskers. The dotted line indicates the identity line. 
Table 3. Accuracy of the multivariable logistic regression model using different probability thresholds to predict calves less than 9 d old (i.e., calves unfit to be transported to auction markets in Canada)

\begin{tabular}{|c|c|c|c|c|c|c|c|c|}
\hline $\begin{array}{l}\text { Probability } \\
\text { threshold }^{1}\end{array}$ & True negative $^{2}$ & False negative $^{3}$ & False positive ${ }^{4}$ & True positive $^{5}$ & Sensitivity & Specificity & $\mathrm{LR}+{ }^{6}$ & $\mathrm{LR}-{ }^{7}$ \\
\hline 0.05 & 3 & 7 & 129 & 145 & 0.954 & 0.023 & 0.494 & 2.026 \\
\hline 0.10 & 8 & 8 & 124 & 144 & 0.947 & 0.061 & 1.152 & 0.868 \\
\hline 0.20 & 31 & 13 & 101 & 139 & 0.914 & 0.235 & 2.746 & 0.364 \\
\hline 0.25 & 41 & 19 & 91 & 133 & 0.875 & 0.311 & 2.485 & 0.402 \\
\hline 0.30 & 50 & 22 & 82 & 130 & 0.855 & 0.379 & 2.617 & 0.382 \\
\hline 0.45 & 85 & 37 & 47 & 115 & 0.757 & 0.644 & 2.645 & 0.378 \\
\hline 0.50 & 90 & 41 & 42 & 111 & 0.730 & 0.682 & 2.528 & 0.396 \\
\hline $0.55^{8}$ & 102 & 45 & 30 & 107 & 0.704 & 0.773 & 2.610 & 0.383 \\
\hline 0.60 & 107 & 61 & 21 & 91 & 0.599 & 0.836 & 2.083 & 0.480 \\
\hline 0.65 & 114 & 70 & 18 & 82 & 0.539 & 0.864 & 1.875 & 0.533 \\
\hline 0.70 & 121 & 81 & 11 & 71 & 0.467 & 0.917 & 1.720 & 0.581 \\
\hline 0.75 & 123 & 95 & 9 & 57 & 0.375 & 0.932 & 1.491 & 0.671 \\
\hline
\end{tabular}

${ }^{1}$ The probability threshold is the predicted probability returned by the logistic regression model based on calf weight and gamma-glutamyl transferase activity concentration. A probability $<$ threshold defines a calf that is fit for being transported (i.e., $\geq 9 \mathrm{~d}$ old), a probability $\geq$ threshold defines a calf unfit for being transported (i.e., $<9 \mathrm{~d}$ old) based on Canadian federal regulation.

${ }^{2}$ True negative $=$ number of calves that are $\geq 9 \mathrm{~d}$ old accurately classified by the model (i.e., < probability threshold).

${ }^{3}$ False negative $=$ number of calves that are $<9 \mathrm{~d}$ old inadequately classified by the model (i.e., $<$ probability threshold).

${ }^{4}$ False positive $=$ number of calves that are $\geq 9 \mathrm{~d}$ old inadequately classified by the model (i.e., $\geq$ probability threshold).

${ }^{5}$ True positive $=$ number of calves that are $<9 \mathrm{~d}$ old accurately classified by the model (i.e., $\geq$ probability threshold).

${ }^{6} \mathrm{LR}+=$ likelihood ratio of a positive test, which is calculated as $\mathrm{LR}+=\mathrm{Se} /(1-\mathrm{Sp})$, where Se $=$ sensitivity and $\mathrm{Sp}=\mathrm{specificity}$.

${ }^{7} \mathrm{LR}-=$ likelihood ratio of a negative test, which is calculated as $\mathrm{LR}+=(1-\mathrm{Se}) / \mathrm{Sp}$.

${ }^{8}$ Optimal threshold that maximizes sensitivity (probability that an unfit calf is adequately classified) and specificity (probability that a calf fit for transport is adequately classified).

$\mathrm{d}$ after the identification was applied. Because of these different steps, an error risk of the true date of birth identification can still be possible.

Like any modeling approach, this study has its limitations. We enrolled animals that were mostly female calves which were intended to stay in sampled dairy herds. It is therefore not certain whether these calves were managed differently from males to be sold for the veal market. The variable prevalence of FPT in the calves' population is, however, compatible with what can be expected in the population of calves found in auction markets as previously discussed. Due to the nature of our study design, the prevalence of female calves is higher than what can be expected in the Québec auction market. In a recent study on 3,821 calves assessed in the auction market, $87 \%$ of the calves were male calves (Marquou et al., 2019). Internal validation performed in (1) running the model only on male calves from the data set and (2) using 500 bootstrap samples with 284 calves obtained from unrestricted sampling with replacement did not show important differences in the logistic regression model (Supplemental File
S3; https://doi.org/10.3168/jds.2019-17601). For this reason, we believe that our model has good internal validity but should definitely be assessed in an external data set in the future as the next step of any prediction modeling approach (Collins et al., 2015). Because BW was indirectly derived from HG measurement, it is unknown if using a standard scale measurement would be helpful for improving model prediction accuracy.

In conclusion, in this study we found that the calves' weight and serum GGT activity concentration can be used to identify calves $<9$ d old (unfit for transportation due to new federal transport regulation). However, the discrimination and accuracy of the model is moderate. Future studies should look to use this test at a population level to determine the prevalence of calves unfit for transport in a specific group of calves.

\section{ACKNOWLEDGMENTS}

Funding was received from the Producteurs Bovins du Québec, Longueil, QC, Canada. The authors have not stated any conflicts of interest. 


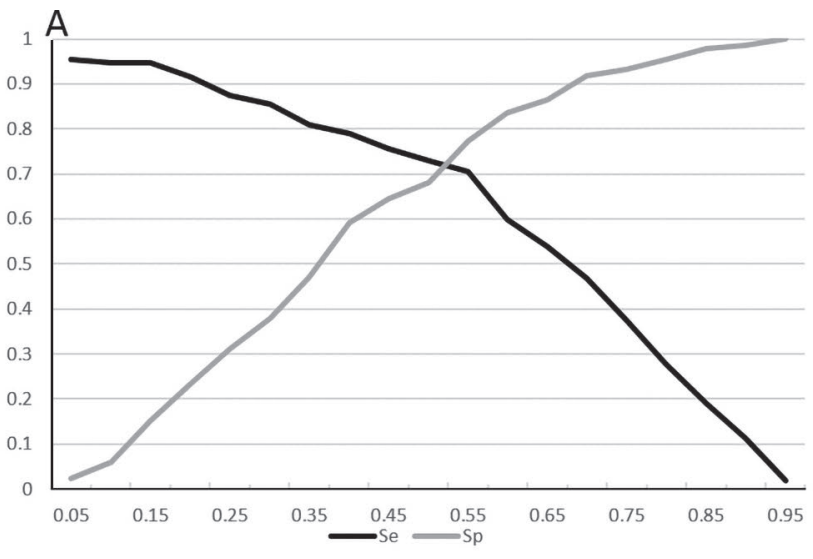

C

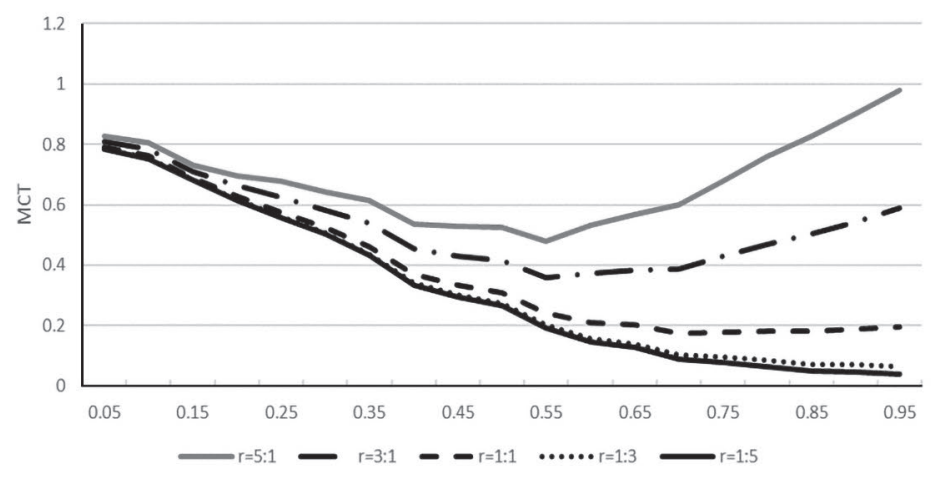

B

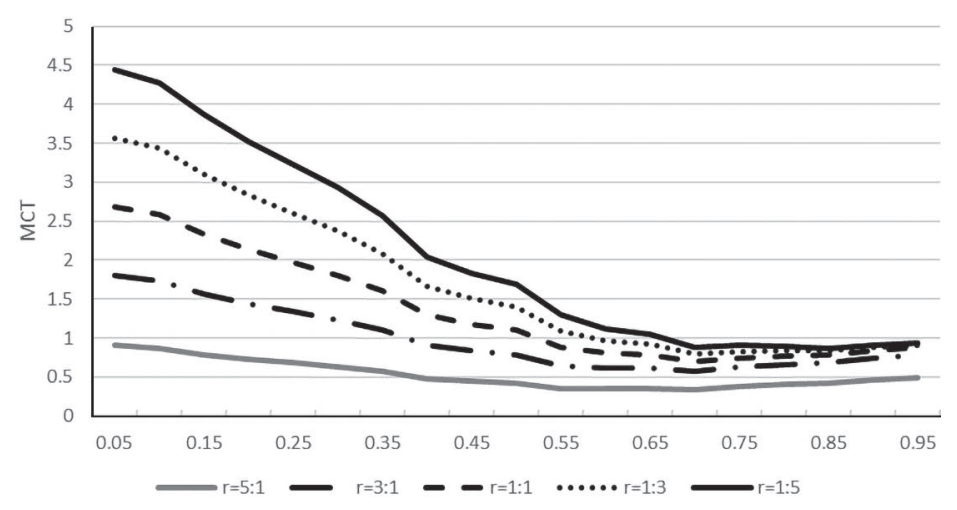

D

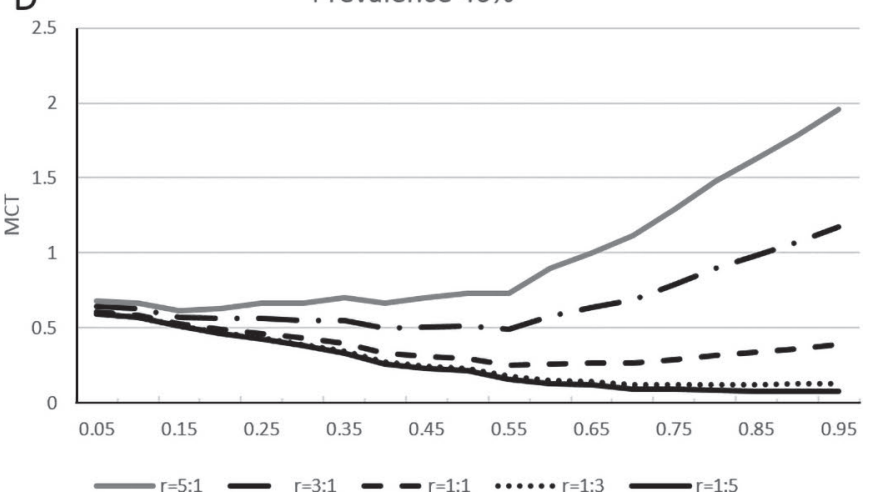

Figure 4. Sensitivity (Se) and specificity ( $\mathrm{Sp}$ ) of the logistic regression model for predicting dairy calves unfit for transport (panel A) and misclassification cost term (MCT) of the cut-offs used depending on expected prevalence of calves <9 d of age of $10 \%$ (panel B), 20\% (panel $\mathrm{C}$ ), and $40 \%$ (panel D), with different relative value of false negative to false positive cases $(5: 1,3: 1,1: 1,1: 3$, and $1: 5)$. $\mathrm{r}=\mathrm{ratio}$ of the cost of false negative case/false positive case.

\section{REFERENCES}

Animal Transport Guides EU. 2019. Guide de bonnes pratiques pour le transport des bovins. Accessed Oct. 23, 2019. http: /animaltransportguides.eu/wp-content/uploads/2017/03/FR -Guides-to-Good-practices-for-the-Transport-of-Cattle.pdf.

Berman, J., D. Francoz, J. Dubuc, and S. Buczinski. 2017. A randomised clinical trial of a metaphylactic treatment with tildipirosin for bovine respiratory disease in veal calves. BMC Vet. Res. 13:176. https://doi.org/10.1186/s12917-017-1097-1.

Braun, J. P., D. Tainturier, C. Laugier, P. Benard, J. P. Thouvenot, and A. G. Rico. 1982. Early variations of blood plasma gammaglutamyl transferase in newborn calves-A test of colostrum intake. J. Dairy Sci. 65:2178-2181. https://doi.org/10.3168/jds.S0022 -0302(82)82479-X.

Buczinski, S., E. Gicquel, G. Fecteau, Y. Takwoingi, M. Chigerwe, and J. M. Vandeweerd. 2018. Systematic review and meta-analysis of diagnostic accuracy of serum refractometry and Brix refractometry for the diagnosis of inadequate transfer of passive immunity in calves. J. Vet. Intern. Med. 32:474-483. https://doi.org/10.1111/ jvim.14893.

Canadian Government. 2019. Règlement modifiant le Règlement sur la santé des animaux. Gazette Officielle du Canada. Accessed Oct. 23, 2019. http://www.gazette.gc.ca/rp-pr/p2/2019/2019-02-20/ html/sor-dors38-fra.html.

Collins, G. S., E. O. Ogundimu, J. A. Cook, Y. L. Manach, and D. G. Altman. 2016. Quantifying the impact of different approaches for handling continuous predictors on the performance of a prog- nostic model. Stat. Med. 35:4124-4135. https://doi.org/10.1002/ sim.6986.

Collins, G. S., J. B. Reitsma, D. G. Altman, and K. G. Moons. 2015. Transparent reporting of a multivariable prediction model for individual prognosis or diagnosis (TRIPOD): The TRIPOD statement. Eur. J. Clin. Invest. 45:204-214. https://doi.org/10.1111/ eci.12376.

Deelen, S. M., T. L. Ollivett, D. M. Haines, and K. E. Leslie. 2014. Evaluation of a Brix refractometer to estimate serum immunoglobulin $\mathrm{G}$ concentration in neonatal dairy calves. J. Dairy Sci. 97:3838-3844. https://doi.org/10.3168/jds.2014-7939.

Dohoo, I. R., W. Martin, and H. E. Stryhn. 2009. Veterinary Epidemiologic Research. VER Inc., Charlottetown, Canada.

Fecteau, G., J. Arsenault, J. Pare, D. C. Van Metre, C. A. Holmberg, and B. P. Smith. 2013. Prediction of serum IgG concentration by indirect techniques with adjustment for age and clinical and laboratory covariates in critically ill newborn calves. Can. J. Vet. Res. 77:89-94.

Fenlon, C., L. O'Grady, M. L. Doherty, and J. Dunnion. 2018. A discussion of calibration techniques for evaluating binary and categorical predictive models. Prev. Vet. Med. 149:107-114. https:// doi.org/10.1016/j.prevetmed.2017.11.018.

Găvan, C., C. Retea, and V. Motorga. 2010. Variation of blood plasma gamma-glutamyltransferase and total protein concentrations in Holstein calves. Anim. Sci. Biotech. 43:242-243.

Godden, S. 2008. Colostrum management for dairy calves. Vet. Clin. North Am. Food Anim. Pract. 24:19-39. https://doi.org/10.1016/ j.cvfa.2007.10.005. 
Hajian-Tilaki, K. 2014. Sample size estimation in diagnostic test studies of biomedical informatics. J. Biomed. Inform. 48:193-204. https://doi.org/10.1016/j.jbi.2014.02.013.

Heinrichs, A. J., G. W. Rogers, and J. B. Cooper. 1992. Predicting body weight and wither height in Holstein heifers using body measurements. J. Dairy Sci. 75:3576-3581. https://doi.org/10.3168/ jds.S0022-0302(92)78134-X.

Hides, S. J., and M. J. A. Hannah. 2005. Drying times of umbilical cords of dairy calves. Aust. Vet. J. 83:371-373. https://doi.org/10 $.1111 /$ j.1751-0813.2005.tb15637.x.

Hosmer, D. W., T. Hosmer, S. Le Cessie, and S. Lemeshow. 1997. A comparison of goodness-of-fit tests for the logistic regression model. Stat. Med. 16:965-980. https://doi.org/10.1002/(SICI)1097 -0258(19970515) 16:9<965::AID-SIM509>3.0.CO;2-O.

Ježek, J., M. Klopčič, and M. Klinkon. 2006. Influence of age on biochemical parameters in calves. Bull. Vet. Inst. Pulawy 50:211-214.

Jongman, E. C., and K. L. Butler. 2014. The effect of age, stocking density and flooring during transport on welfare of young dairy calves in Australia. Animals (Basel) 4:184-199. https://doi.org/ 10.3390/ani4020184.

Mandrekar, J. N. 2010. Receiver operating characteristic curve in diagnostic test assessment. J. Thorac. Oncol. 5:1315-1316. https:// doi.org/10.1097/JTO.0b013e3181ec173d.

Marquou, S., L. Blouin, H. Djakite, R. Laplante, and S. Buczinski. 2019. Health parameters and their association with price in young calves sold at auction for veal operations in Québec, Canada. J. Dairy Sci. 102:6454-6465. https://doi.org/10.3168/jds.2018-16051.

Masmeijer, C., B. Devriendt, T. Rogge, K. van Leenen, L. De Cremer, B. Van Ranst, P. Deprez, E. Cox, and B. Pardon. 2019. Randomized field trial on the effects of body weight and short transport on stress and immune variables in 2- to 4 -week-old dairy calves. J. Vet. Intern. Med. 33:1514-1529. https://doi.org/10.1111/jvim .15482 .

New Zealand Legislation. 2018. Animal Welfare (Care and Procedures) Regulations 2018. Accessed Oct. 23, 2019. http://www.legislation .govt.nz/regulation/public/2018/0050/latest/whole.html.

NFACC. 2017. Code of Practice for the Care and Handling of Veal Cattle. National Farm Animal Care Council. Accessed Oct. 23, 2019. https://www.nfacc.ca/codes-of-practice/veal-cattle.

Nielsen, B. L., L. Dybkjaer, and M. S. Herskin. 2011. Road transport of farm animals: Effects of journey duration on animal welfare. Animal 5:415-427. https://doi.org/10.1017/S1751731110001989.

Pardon, B., J. Alliet, R. Boone, S. Roelandt, B. Valgaeren, and P. Deprez. 2015. Prediction of respiratory disease and diarrhea in veal calves based on immunoglobulin levels and the serostatus for respiratory pathogens measured at arrival. Prev. Vet. Med. 120:169-176. https://doi.org/10.1016/j.prevetmed.2015.04.009.

Parish, S. M., J. W. Tyler, T. E. Besser, C. C. Gay, and D. Krytenberg. 1997. Prediction of serum IgG1 concentration in Holstein calves using serum gamma glutamyltransferase activity. J. Vet. Intern. Med. 11:344-347. https://doi.org/10.1111/j.1939-1676.1997 .tb00478.x.
Pempek, J., D. Trearchis, M. Masterson, G. Habing, and K. Proudfoot. 2017. Veal calf health on the day of arrival at growers in Ohio. J. Anim. Sci. 95:3863-3872. https://doi.org/10.2527/jas2017 .1642 .

Renaud, D. L., T. Duffield, S. LeBlanc, and D. F. Kelton. 2018a. Validation of methods for practically evaluating failed passive transfer of immunity in calves arriving at a veal facility. J. Dairy Sci. 101:9516-9520. https://doi.org/10.3168/jds.2018-14723.

Renaud, D. L., M. W. Overton, D. F. Kelton, S. J. LeBlanc, K. C. Dhuyvetter, and T. F. Duffield. 2018b. Effect of health status evaluated at arrival on growth in milk-fed veal calves: A prospective single cohort study. J. Dairy Sci. 101:10383-10390. https://doi .org/10.3168/jds.2018-14960.

Steyerberg, E. W., A. J. Vickers, N. R. Cook, T. Gerds, M. Gonen, N. Obuchowski, M. J. Pencina, and M. W. Kattan. 2010. Assessing the performance of prediction models: A framework for traditional and novel measures. Epidemiology 21:128-138. https://doi.org/10 .1097/EDE.0b013e3181c30fb2.

Stilwell, G., and R. Carvalho. 2011. Clinical outcome of calves with failure of passive transfer as diagnosed by a commercially available IgG quick test kit. Can. Vet. J. 52:524-526.

Timsit, E., R. Leguillette, B. J. White, R. L. Larson, and S. Buczinski. 2018. Likelihood ratios: An intuitive tool for incorporating diagnostic test results into decision-making. J. Am. Vet. Med. Assoc. 252:1362-1366. https://doi.org/10.2460/javma.252.11.1362.

Villarroel, A., T. B. Miller, E. D. Johnson, K. R. Noyes, and J. K. Ward. 2013. Factors affecting serum total protein and immunoglobulin $\mathrm{G}$ concentration in replacement dairy calves. J. Adv. Dairy Res. 1:1000106.

Weaver, D. M., J. W. Tyler, D. C. VanMetre, D. E. Hostetler, and G. M. Barrington. 2000. Passive transfer of colostral immunoglobulins in calves. J. Vet. Intern. Med. 14:569-577. https://doi.org/10 .1111/j.1939-1676.2000.tb02278.x.

Wilm, J., J. H. C. Costa, H. W. Neave, D. M. Weary, and M. A. G. von Keyserlingk. 2018. Technical note: Serum total protein and immunoglobulin $\mathrm{G}$ concentrations in neonatal dairy calves over the first 10 days of age. J. Dairy Sci. 101:6430-6436. https://doi.org/ $10.3168 /$ jds. 2017-13553.

Winder, C. B., D. F. Kelton, and T. F. Duffield. 2016. Mortality risk factors for calves entering a multi-location white veal farm in Ontario, Canada. J. Dairy Sci. 99:10174-10181. https://doi.org/10 .3168/jds.2016-11345.

\section{ORCIDS}

S. Buczinski @ https://orcid.org/0000-0002-8460-4885

J. Dubuc $\odot$ https://orcid.org/0000-0003-1013-8372

V. Bourgeois @ https://orcid.org/0000-0001-6089-8105 